\title{
A responsabilidade civil e seus critérios para a quantificação do dano moral: as jurisprudências brasileira e espanhola, em perspectiva comparada
}

\author{
Civil responsibility and its criteria for the quantification of moral \\ damage: the brazilian and spanish jurisprudence in a compared \\ perspective
}

\author{
Bárbara Gomes Lupetti Baptista ${ }^{1}$
}

Daniel Navarro Puerari ${ }^{2}$

\section{RESUMO}

Este trabalho problematiza, a partir de análise doutrinária e, especialmente, jurisprudencial, com foco nas decisões proferidas pelos Tribunais Superiores do Brasil e da Espanha, os critérios para a quantificação do dano moral e o tratamento conferido aos conflitos decorrentes de responsabilidade civil por violação ao direito da personalidade em ambos os sistemas de justiça, em perspectiva comparada. O contraste e a análise jurisprudencial permitiu perceber que, no Brasil, o Superior Tribunal de Justiça tem um papel importante na concessão das indenizações e que, apesar da súmula 7, que impediria o revolvimento das questões fáticas atinentes à responsabilidade civil, ainda assim, a corte pode, casuisticamente, reduzir ou aumentar o valor do dano moral concedido nas instâncias estaduais. Na Espanha, diferentemente do que ocorre em nosso país, o sistema processual confere maior autonomia aos magistrados e tribunais de instância inferior, no que se refere ao tratamento e, notadamente, à quantificação do dano moral, sendo certo que o papel da corte superior, de cassação, é menos centralizador e, consequentemente, mais restrito em relação ao que se verificou no Brasil.

\section{Palavras-chave}

Indenizações; Dano Moral; Critérios de Quantificação; Brasil; Espanha; Direito Comparado.

\footnotetext{
${ }^{1}$ Professora do Programa de Pós-Graduação em Direito da Universidade Veiga de Almeida(PPGD-UVA). Professora da Faculdade de Direito da Universidade Federal Fluminense.Pesquisadora do INCT/InEAC. blupetti@globo.com

2 Professor dos Cursos de Graduação e Pós-Graduação da Universidade Estácio de Sá. Doutorando do Programa de Pós-Graduação em Direito da Universidade Veiga de Almeida . dpuerari@gmail.com
} 


\begin{abstract}
Based on the opinions of jurists and, especially, on an analysis of precendent cases focused on rulings entered by Higher Courts of Brazil and Spain, this paper questions the criteria for the quantification of mental distress and the treatment of conflicts arising from civil liability for violations of personality rights in both systems of justice, in a comparative perspective. The contrast and the analysis of precendent cases made it possible to notice that, in Brazil, the Superior Court of Justice plays an important role in the grant of damages and, despite precedent 7, which would prevent the revolving of the factual issues related to civil liability, the Court may, on a case-by-case basis, reduce or increase the amount of mental distress granted in state instances. In Spain, unlike our country, the procedural system gives greater autonomy to judges and courts of lower instance, in regard to the treatment and, in particular, to the quantification of mental distress. The role of the superior court, of cassation, for sure is less centralizing and, consequently, more restricted in relation to what was seen in Brazil.
\end{abstract}

\title{
Keywords
}

Indemnities; Moral Damage; Quantification Criteria; Brazil; Spain; Comparative Law.

\section{Introdução: explicitando a problemática e os objetivos da pesquisa}

Este trabalho problematiza, a partir da análise da doutrina e, especialmente, das decisões judiciais proferidas pelos Tribunais Superiores do Brasil e da Espanha, os critérios para a quantificação do dano moral e o tratamento conferido aos conflitos decorrentes de responsabilidade civil por violação ao direito da personalidade em ambos os sistemas de justiça, em perspectiva comparada.

Para explorar a temática selecionada neste trabalho, analisamos comparativamente os dois sistemas jurídicos, o brasileiro e o espanhol, e verificamos que, apesar das semelhanças, por se tratarem de países de tradição pautada na Civil Law, cada qual possui também peculiaridades que os distinguem ${ }^{3}$, circunstâncias que contribuíram muito para uma releitura do nosso próprio sistema, a partir de uma perspectiva mais aprofundada.

\footnotetext{
${ }^{3}$ Vejamos uma breve explicação do sistema jurídico espanhol: As fontes do ordenamento jurídico espanhol estão definidas no artigo $1 .^{\circ}$ do Código Civil: 1 . As fontes do ordenamento jurídico espanhol são a lei, o costume e os princípios gerais do direito. 2. São nulas as disposições que entrem em contradição com outras de nível superior. 3. O costume rege apenas na falta de preceito jurídico válido, sempre que não seja contrário à moral ou à ordem pública e desde que seja fundamentado. 4. Os usos jurídicos que não sejam meramente interpretativos de uma declaração de vontade são considerados costume. 5. Os princípios gerais do direito aplicam-se na ausência da lei ou do costume, sem prejuízo da influência que exercem sobre o ordenamento jurídico. 6.As normas jurídicas contidas nos tratados internacionais só se aplicam diretamente em Espanha depois de passarem a integrar a ordem jurídica interna, mediante a sua publicação integral no Boletim Oficial do Estado. 7. A jurisprudência completa o ordenamento jurídico com a doutrina que, de modo reiterado, for estabelecida pelo Supremo Tribunal
} 
A pesquisa pontuou que, assim como no Brasil, também na Espanha a principal fonte do direito é a lei; e, nos dois países, há a obrigatoriedade de o juiz julgar uma demanda submetida à apreciação do poder judiciário, sendo certo que, em não havendo lei específica sobre o caso, deve-se utilizar outras fontes do Direito ${ }^{4}$.

A problemática tratada nesse artigo se concentra justamente nesse ponto, na medida em que verificamos que, nem no Brasil, tampouco no país ibérico, há previsão legal que fixe critérios concretos e objetivos para o arbitramento de quantia indenizatória quando se verifica lesão a bem imaterial, sendo fundamental o estudo da jurisprudência para tratar de entender como, na administração de conflitos e nos casos concretos submetidos ao Judiciário de ambos os países, são tratados os pedidos de indenização por danos morais.

De fato, diferentemente do que ocorre em nosso sistema, no direito espanhol não há a expressa menção à categoria "indenização por danos morais", havendo, na constituição, uma referência mais genérica na expressão "direito à integridade física e moral”.

O dano moral é indenizado, na Espanha, em razão da interpretação conferida ao artigo 1092 do Código Civil espanhol, que obriga o causador do dano a repará-lo, se agiu com culpa ou negligência, não havendo, no entanto, menção literal à lesão imaterial ou "indenização por dano moral".

Assim, no sistema espanhol, a interpretação semântica conferida ao termo daño, de forma ampliativa, contempla todas as espécies de dano, inclusive o dano moral.

De nossa parte, no Brasil, dispomos da categoria em nossa CRFB/88, art. $5^{\circ}$, que alçou a indenização imaterial à categoria de direito fundamental.

Sendo assim, por contraste, pretendemos verificar, concretamente, como se dá o tratamento das ações por indenização de dano moral no Brasil e na Espanha, sendo que, mais especificamente, pretendemos compreender o papel das cortes superiores nesses casos.

Ou seja, pretendemos compreender se, na Espanha, no que se refere à fixação do quantum indenizatório, a corte superior se debruça sobre detalhes do arbitramento da indenização ou se teria apenas o compromisso de interpretar o direito; e se os critérios utilizados pela jurisprudência espanhola, no que se refere à quantificação do dano, são de livre

no quadro da interpretação e da aplicação da lei, do costume e dos princípios gerais do direito. 8. Os juízes e os tribunais têm o dever inescusável de, em todo caso, resolver os processos que apreciem, tendo em conta o sistema de fontes estabelecido. Disponível em: < https://e-justice.europa.eu/content_member_state_law-6-esmaximizeMS-pt.do?member=1>. Acesso em 29 mai. 2017.

${ }^{4}$ Assim determina o artigo $4^{\circ}$. da LINDB: Art. 4ํ Quando a lei for omissa, o juiz decidirá o caso de acordo com a analogia, os costumes e os princípios gerais de direito. 
arbitramento pelos juízes e tribunais de $2^{\text {a }}$ instância, ou se, assim como ocorre no Brasil, também há um controle pelo Tribunal Superior Espanhol (lá também denominado de corte de cassação), última instância judicial federal daquele país.

Apesar das diferenças que marcam ambos os sistemas jurídicos, brasileiro e espanhol, é certo, no que se refere ao direito à indenização por dano moral, que ambas as tradições o preveem em suas respectivas constituições federais, uma literalmente (no Brasil) e outra nem tanto (Espanha), alçando-os à categoria de direito fundamental.

Além disso, como dito, são os Tribunais Superiores de ambos os países - aqui, o Superior Tribunal de Justiça, e lá, os Tribunales Superiores de Justicia (TSJ) - que julgam, em âmbito federal, o direito à indenização por violação a direito da personalidade, sendo certo que, em ambos os sistemas, inexistem critérios objetivos e concretos para o arbitramento do valor do dano moral, características que se mostraram interessantes para tratar os pontos de convergência dos argumentos enfrentados na jurisprudência dos dois países e, com isso, a partir da identificação de semelhanças e de diferenças, repensar o sistema brasileiro da responsabilidade civil, de uma forma mais aprofundada.

O trabalho fora desenvolvido de forma a, primeiramente, abordar aspectos gerais da indenização por danos morais nos dois sistemas jurídicos estudados, para, então, em seguida, verificarmos suas semelhanças e diferenças, tratando, especificamente, da análise das jurisprudências das cortes superiores de ambos os sistemas de justiça.

Acreditamos que a análise de ordenamentos estrangeiros pode contribuir bastante para a compreensão do nosso próprio Direito, ademais, pode ser um facilitador na busca de soluções, que, fechados em nosso sistema, ainda não vislumbramos.

É, portanto, nesse sentido que caminha este trabalho e com base nessas perspectivas que sistematizamos e problematizamos as temáticas que elegemos explorar doravante.

\section{A indenização por dano moral como direito fundamental no Brasil e na Espanha}

No ordenamento jurídico brasileiro é pacífica a questão acerca da natureza do dano causado à direito imaterial da pessoa e à possibilidade de sua reparação pelo causador do dano.

Na CRFB/1988 há expressa previsão, justamente em seu título II, correspondente aos direitos e garantias fundamentais: 
Art. $5^{\circ}$ Todos são iguais perante a lei, sem distinção de qualquer natureza, garantindo-se aos brasileiros e aos estrangeiros residentes no País a inviolabilidade do direito à vida, à liberdade, à igualdade, à segurança e à propriedade, nos termos seguintes [...]

$\mathrm{V}$ - é assegurado o direito de resposta, proporcional ao agravo, além da indenização por dano material, moral ou à imagem [...]

X - são invioláveis a intimidade, a vida privada, a honra e a imagem das pessoas, assegurado o direito a indenização pelo dano material ou moral decorrente de sua violação [...].

Conforme observado, no Brasil, a reparação por dano moral possui status constitucional, estando sua previsão no rol de cláusulas pétreas, sendo classificada como norma de eficácia plena, ou seja, com aplicação imediata, independentemente de lei que a complemente ou regule.

No Código Civil brasileiro, por sua vez, encontra-se, igualmente, nos artigos 186 e 927, previsão para a indenização por dano causado por ato ilícito, que se conceitua como o ato que viola direito e causa dano a outrem, ainda que exclusivamente moral.

Do mesmo modo, na Constituição espanhola, no título I, Sección $1^{a}$., referente aos Derechos fundamentales y de las libertades públicas, em seu artigo 15, declara-se o direito à integridade física e moral, sugerindo tratar, a moral, como um direito fundamental passível de indenização em caso de violação:

Artigo 15. Todos têm direito à vida e à integridade física e moral, sem que, em nenhum caso, possam ser submetidos a tortura nem a penas ou tratamentos desumanos ou degradantes. Fica abolida a pena de morte, salvo as leves penas militares em tempos de guerra. (tradução livre) $)^{5}$

$\mathrm{Na}$ esfera infraconstitucional, observando o artigo 1092 do Código Civil espanhol, notamos que também há expressa menção à indenização por dano moral ou qualquer ofensa imaterial: "Aquele que por ação ou omissão causa dano a outrem, agindo com culpa ou negligência, está obrigado a reparar dano causado.”. (tradução livre) ${ }^{6}$

\footnotetext{
${ }^{5}$ Texto original em espanhol: Artículo 15. Todos tienen derecho a la vida y a la integridad física y moral, sin que, en ningún caso, puedan ser sometidos a tortura ni a penas o tratos inhumanos o degradantes. Queda abolida la pena de muerte, salvo lo que puedan disponer las leyes penales militares para tiempos de guerra.

${ }^{6}$ Texto original em espanhol: Art. 1092. El que por acción u omisión causa daño a otro, interviniendo culpa o negligencia, está obligado a reparar el daño causado.
} 
Entretanto, por ser o diploma civilista espanhol um decreto real de 24 de julho de 1889, ou seja, bastante anterior à atual constituição, ratificada no ano de 1978, se fez necessário realizar uma releitura constitucional de seus dispositivos.

E assim ocorreu com seu artigo 1902, que precisou contemplar uma noção de "dano" de forma mais ampla do que apenas a compreensão do dano material.

Como vimos, isso ocorre, principalmente, em razão de a Constituição daquele país assegurar a todos o direito à integridade física e moral. Desta forma, é necessária a realização de um trabalho hermenêutico na aplicação do artigo 1092, interpretando-o de forma sistêmica e, no que se refere aos seus efeitos, de forma ampliativa ou extensiva.

Verifica-se, portanto, no que se refere ao direito à indenização por dano moral, que ambas as culturas jurídicas, brasileira e espanhola, o preveem em suas respectivas constituições federais, uma de forma mais literal (no Brasil), e outra, por questão histórica, de forma menos literal (Espanha), sendo que, em ambas as tradições, os danos estão alçados à categoria de direito fundamental.

Sendo assim, percebemos que a reparação por dano moral nos países analisados, Brasil e Espanha, possui status constitucional.

Cabe ainda ressaltar, que é pacífico na doutrina e na jurisprudência pátrias, o entendimento de que o juiz deve ser livre e independente na hora de arbitrar o valor da indenização por dano moral. E, mesmo após a vigência do Novo CPC, que tratou de determinar, no art. 292, inciso V, que cabe ao autor indicar, na petição inicial, o valor pretendido a título de dano moral, ainda assim, o magistrado tem liberdade na fixação do quantum indenizatório, nos limites objetivos do pedido.

Isso ocorre principalmente porque, em nosso ordenamento, há o denominado princípio da reparação integral dos danos, respondendo o causador de uma lesão por toda a sua extensão. Não fosse essa liberdade, teríamos, como ocorre em alguns países, o tabelamento (legal ou jurisprudencial) da indenização por danos morais, técnica muito criticada pelos estudiosos da responsabilidade civil.

Sobre esse tema, vejamos a posição de Carlos Alberto Bittar (2015, p. 30-31):

A propósito, filiamo-nos ao sistema aberto, pois se mostra mais eficiente para o alcance dos objetivos citados. Sustentamos que nem deve nem existir limite máximo em leis sobre a matéria - como ocorre em certos países diante do princípio fundamental dessa teoria, que é o da ilimitação da responsabilidade do patrimônio do lesante, a uma, porque se pode mostrar 
irreal em certas situações, e, a duas, porque tem sido ele derreado, em nossos tribunais, pela aplicação da regra do cúmulo ou da cumulação de indenizações sob os dois fundamentos possíveis, o do risco e o da culpa, como vem acontecendo em acidentes de transportes e acidentes de trabalho. A tônica desse entendimento reside na necessidade absoluta e prioritária de cabal satisfação do interesse lesado, que os índices ou os valores tarifados quase sempre não propiciam.

Deve-se, pois, confiar à sensibilidade do magistrado a determinação da quantia devida, obedecidos os pressupostos mencionados. O contato com a realidade processual e com a realidade fática permite-lhe aferir o valor adequado à situação concreta.

Curiosamente, também no direito espanhol existe o chamado princípio da integral reparação dos danos e prejuízos. Tal princípio, também conhecido como "restitutio in integrum”, busca, assim como posto na dogmática brasileira, a mais perfeita equivalência possível entre os danos sofridos e a reparação da vítima (CASTILLO MARTíNEZ, 2003; BUSTO LAGO e PEÑA LÓPEZ, 1997).

O que se coloca, portanto, como questão principal acerca do princípio da reparação integral e do direito à indenização é, tanto no Brasil, quanto na Espanha, a ausência de critérios objetivos para a fixação do quantum indenizatório dos danos morais, que costuma ser arbitrado de forma livre pelo magistrado, em função de seu contato direto com os fatos e com o processo, e que, na ocasião da revisão pelos Tribunais Superiores, assume contornos curiosos e distintos, como se verá mais adiante.

\section{Análise jurisprudencial do arbitramento das indenizações por danos morais no Brasil e na Espanha: os limites e as possibilidades das Cortes Superiores no enfrentamento do quantum indenizatório}

No Brasil, o órgão do poder Judiciário responsável por uniformizar a jurisprudência sobre matéria que envolva lei federal é o Superior Tribunal de Justiça.

É cediço, na doutrina e na jurisprudência, que o referido órgão, no que se refere à competência recursal, não é uma nova instância para reanálise do mérito de uma demanda, mas apenas averigua se houve ofensa à lei federal. ${ }^{7}$

\footnotetext{
${ }^{7}$ O Superior Tribunal de Justiça - STJ foi criado pela Constituição Federal de 1988. A Corte é responsável por uniformizar a interpretação nacional da lei federal. O Tribunal atua, em última instância, para solução de conflitos de natureza infraconstitucional. Funciona como órgão de convergência do Direito Pátrio ao julgar causas oriundas de todo o território nacional, em todas as vertentes jurisdicionais não especializadas. É também chamado de "Tribunal da Cidadania", devido à sua origem na "Constituição Cidadã". Sua competência
} 
Nesse sentido, há a súmula 7 do $\mathbf{S T J}$, que expõe: A pretensão de simples reexame de prova não enseja recurso especial. Entendimento idêntico observamos no Supremo Tribunal Federal, que editou a Súmula 279 do STF, nos seguintes termos: para simples reexame de prova não cabe recurso extraordinário.

Muito embora o supracitado entendimento, notamos que o STJ, por vezes, supera a sua súmula 7 para reformar o mérito de uma demanda indenizatória envolvendo condenação em dano moral, utilizando como argumento a não observância dos princípios da proporcionalidade e razoabilidade pelos tribunais de segunda instância e enfrentando, portanto, o valor do dano arbitrado na instância inferior.

Quando analisada uma sentença na qual a fixação do valor supera o que os ministros julgadores entendem por razoável e proporcional, o referido tribunal, contrariando o teor da sua própria súmula, reanalisa o mérito, seja para reduzir a indenização que considere excessivamente alta, seja para majorar a condenação fixada em patamares ínfimos.

Segundo análise de sua jurisprudência, do STJ, percebemos que até mesmo para excluir a indenização fixada pelo tribunal, a referida súmula é superada, conforme já observado em pesquisas anteriores sobre o tema (LUPETTI BAPTISTA e PUERARI, 2016).

As referidas súmulas, como visto, cristalizam uma posição bastante rígida no sentido de registrar que as cortes superiores não funcionam como terceira e/ou quarta instâncias revisoras, servindo, em vez disso, como tribunais de pacificação da interpretação da Constituição Federal e das leis federais. No entanto, a prática forense tem demonstrado que, em situações ocasionais, e seletivas, os referidos Tribunais Superiores e, para este trabalho, mais especificamente o STJ, superam o óbice das súmulas e enfrentam questões de fato, posicionando-se no sentido de majorar ou minorar indenizações por danos morais concedidas nas instâncias inferiores.

Vejamos abaixo recentes informativos do $\mathrm{STJ}^{8}$, que reanalisam o meritum causae para majorar, reduzir ou excluir o valor atribuído em acórdão de segunda instância à título de danos morais em situações que envolveram o direito ao esquecimento, morte de parente, acidente de trânsito e direito à imagem, elucidando que, em nossa cultura jurídica, a corte

originária e recursal estão previstas no art. 105 da Constituição Federal. Fonte: http://www.stj.jus.br/portal_stj/arquivos/conheca_o_stj_web.pdf Acessado em 03.12.2016.

8 Publicação periódica que divulga teses firmadas pelo STJ, selecionadas pela novidade no âmbito do Tribunal e pela repercussão no meio jurídico. Além disso, são disponibilizados links para o acesso a outros produtos relacionados às teses publicadas. Disponível em: https://ww2.stj.jus.br/jurisprudencia/externo/informativo/?aplicacao=informativo.ea.>. Acesso em 03 dez. 2016. 
superior brasileira se imiscui no valor arbitrado pelas instâncias inferiores a título de indenização:

$\begin{array}{llllll}\text { Informativo } & \mathbf{n}^{\circ} & 0505 . & \text { QUARTA } & \text { TURMA. DIREITO CIVIL. } \\ \text { RESPONSABILIDADE } & \text { CIVIL. DANO MORAL POR MORTE DE }\end{array}$ PARENTE. A indenização por dano moral decorrente da morte de parente deve ser fixada de forma global à família do falecido e com observância ao montante de quinhentos salários mínimos, usualmente adotado pelo STJ, ressalvada a possibilidade de acréscimo de valor em se tratando de famílias numerosas. Embora amparado em normas constitucionais, o direito à indenização plena dos danos morais não é absoluto, podendo ser ponderado com outros direitos fundamentais de igual grandeza. O STJ tem estabelecido critérios razoavelmente objetivos para liquidar o dano moral, não com a finalidade de tarifar a compensação pelo abalo, mas para buscar soluções equânimes, na medida em que situações assemelhadas devem ser solucionadas também de forma semelhante. Em caso de morte de familiar, o valor usual adotado são quinhentos salários mínimos. O sistema de responsabilidade civil atual, com base no art. 944, parágrafo único, do $\mathrm{CC}$, rechaça indenizações ilimitadas que alcançam valores que, a pretexto de reparar integralmente vítimas de ato ilícito, revelam nítida desproporção entre a conduta do agente e os resultados ordinariamente dela esperados. Simplesmente multiplicar o valor que se concebe como razoável pelo número de autores da demanda pode tornar a obrigação do causador do dano extensa e distante de padrões baseados na proporcionalidade e razoabilidade, uma vez que se analisa apenas a extensão do dano para o arbitramento da indenização, desconsiderando o outro extremo da relação, que é a conduta do causador do dano, com a valoração de sua reprovabilidade e as circunstâncias do caso concreto. A solução adequada deve, a um só tempo, sopesar a extensão do dano e a conduta de seu causador; pois, embora por vezes os atingidos pelo fato danoso sejam vários, a conduta do réu é única, e sua reprovabilidade é igualmente uma só, o que deve ser considerado na fixação da indenização por dano moral. Não se desconhece que o dano moral é uma violação individualmente experimentada pela pessoa, porém a solução apresentada considera, a um só tempo, tanto a individualidade dos atingidos pelo dano quanto a conduta do causador. Em se tratando de famílias numerosas, o arbitramento da indenização de forma global, desconsiderando o número de integrantes, também pode acarretar injustiças, de modo que o valor pode ser elevado gradativamente na medida em que cresça também o número de beneficiados, evitando que os quinhões individuais se tornem irrisórios. Se, para o arbitramento da indenização, deve ser considerado o número de autores, certamente uma ação proposta apenas por parte dos legitimados conduzirá à indenização de menor valor, não impedindo que, futuramente, outros legitimados proponham sua pretensão, desde que a soma não atinja patamares desarrazoados. Precedentes citados: $\mathrm{AgRg}$ no Ag 1.378.016-MS, DJe 22/8/2012; REsp 989.284-RJ, DJe 22/8/2011; REsp 936.792-SE, DJ 22/10/2007; REsp 825.275-SP, DJe 8/3/2010 ; REsp 210.101-PR, DJe 9/12/2008; REsp 163.484-RJ, DJ 13/10/1998 ; REsp 687.567-RS, DJ 13/3/2006; REsp 1.139.612-PR, DJe 23/3/2011; REsp 959.780-ES, DJe 6/5/2011. REsp 1.127.913-RS, Rel. originário Min. Marco Buzzi, Rel. para acórdão Min. Luis Felipe Salomão , julgado em 20/9/2012. 
Informativo $n^{\circ}$ 0493. QUARTA TURMA. DANO MORAL. DIREITO DE INFORMAR E DIREITO À IMAGEM. O direito de informar deve ser analisado com a proteção dada ao direito de imagem. O Min. Relator, com base na doutrina, consignou que, para verificação da gravidade do dano sofrido pela pessoa cuja imagem é utilizada sem autorização prévia, devem ser analisados: (i) o grau de consciência do retratado em relação à possibilidade de captação da sua imagem no contexto da imagem do qual foi extraída; (ii) o grau de identificação do retratado na imagem veiculada; (iii) a amplitude da exposição do retratado; e (iv) a natureza e o grau de repercussão do meio pelo qual se dá a divulgação. De outra parte, o direito de informar deve ser garantido, observando os seguintes parâmetros: (i) o grau de utilidade para o público do fato informado por meio da imagem; (ii) o grau de atualidade da imagem; (iii) o grau de necessidade da veiculação da imagem para informar o fato; e (iv) o grau de preservação do contexto originário do qual a imagem foi colhida. No caso analisado, emissora de TV captou imagens, sem autorização, de funcionário de empresa de assistência técnica durante visita para realização de orçamento para conserto de uma televisão que, segundo a emissora de TV, estava apenas com um fusível queimado. $\mathrm{O}$ orçamento realizado englobou outros serviços, além da troca do fusível. A imagem do funcionário foi bem focalizada, permitindo sua individualização, bem como da empresa em que trabalhava. Não houve oportunidade de contraditório para que o envolvido pudesse provar que o aparelho tinha outros defeitos, além daquele informado pela rede de TV. Assim, restou configurado dano moral por utilização indevida da imagem do funcionário. Noutro aspecto analisado, o Min. Relator destacou a pacífica jurisprudência do STJ que possibilita a revisão do montante devido a título de dano moral, quando o valor for exorbitante ou irrisório, observados os princípios da proporcionalidade e da razoabilidade. Nesse contexto, a Turma entendeu desproporcional a fixação da verba indenizatória em $\mathbf{R} \$ 100$ mil, reduzindo-a a $\mathbf{R} \$ 30 \mathrm{mil}$. Precedentes citados: REsp 267.529-RJ, DJ de 18/12/2000; REsp 1.219.197RS, DJe de 17/10/2011; REsp 1.005.278-SE, DJe de 11/11/2010; REsp 569.812-SC, DJ de 1\%/2005. REsp 794.586-RJ, Rel. Min. Raul Araújo, julgado em 15/3/2012.

Informativo $n^{\circ}$ 0470. TERCEIRA TURMA. CRITÉRIOS. FIXAÇÃO. VALOR. INDENIZAÇÃO. ACIDENTE. TRÂNSITO. Trata-se, na origem, de ação de reparação de danos materiais e morais em razão de acidente automobilístico que vitimou a esposa do recorrente. O Min. Relator, ao analisar, pela primeira vez, em sessão de julgamento, um recurso especial sobre a quantificação da indenização por dano moral, procura estabelecer um critério razoavelmente objetivo para o arbitramento da indenização por dano moral. (...) Logo, o método mais adequado para um arbitramento razoável da indenização por dano extrapatrimonial resulta da união dos dois critérios analisados (valorização sucessiva tanto das circunstâncias como do interesse jurídico lesado). Assim, na primeira fase, arbitra-se o valor básico ou inicial da indenização, considerando o interesse jurídico lesado, em conformidade com os precedentes acerca da matéria e, na segunda fase, procede-se à fixação da indenização definitiva, ajustando-se o seu montante às peculiaridade do caso com base nas suas circunstâncias. REsp 959.780ES, Rel. Min. Paulo de Tarso Sanseverino, julgado em 26/4/2011. 
Na Espanha, a análise das decisões do Tribunal de Cassação ${ }^{9}$, tribunal superior da justiça espanhola, que naquele país tem função aproximada à do nosso STJ, aferimos que a análise do quantum indenizatório arbitrado pelos danos morais sofridos é de discricionariedade das instâncias inferiores (juízes de primeiro grau e tribunais de províncias), não se permitindo à corte superior que (re)enfrente o quantum indenizatório.

Desta forma, percebe-se que será irretocável o valor arbitrado a título de indenização advinda de lesão a direito da personalidade, ainda que fixado em patamar excessivamente alto ou ínfimo.

Na verdade, nos julgados pesquisados, sequer há a análise desse mérito. Há apenas a clara menção de que o poder de fixação do valor da indenização é do juiz ou tribunal de “instância”, na província, não se permitindo à corte superior reanalisar o quantum.

Vejamos a seguir algumas decisões recentes da corte de cassação espanhola, que abordam justamente a questão em comento, demonstrando os limites do papel da corte superior espanhola, estando, os referidos julgados, colacionados na obra intitulada Tratado Jurisprudencial de Responsabilidad por Daños, coordenada por Maria Serrano Fernández (2013), que é referência naquele país:

[...] Quantificação do dano. A faculdade dos tribunais em moderar o dano atribuído a responsabilidade civil escapa do controle de cassação porquanto esta faculdade é de utilização discricionária, segundo constante doutrina desta sala. "A aplicação do disposto no artigo 1103 do código civil sobre a moderação da responsabilidade nascida de negligência é faculdade discricionária dos tribunais de instância, atendidas as circunstâncias do caso; e não constituem um mandato para o julgador", disse a sentença a 29 de novembro de 1985 antes citada [STS. 09\02\87 (TOL 1739652)].

\footnotetext{
${ }^{9}$ No que diz respeito ao caráter unipessoal ou colegial dos órgãos, estes são todos unipessoais, com exceção do Supremo Tribunal, da Audiência Nacional, dos tribunais superiores de justiça e dos tribunais provinciais. O Supremo Tribunal é formado pelo seu presidente, pelos presidentes de divisão e pelos magistrados estipulados por lei para cada uma das suas divisões e secções. Possui cinco divisões: Civil, Penal, Contencioso Administrativo, Laboral e Militar. A Audiência Nacional é formada pelo seu presidente, pelos presidentes de divisão e pelos magistrados estipulados por lei para cada uma das suas divisões (de Apelação, Penal, Contencioso Administrativo e Laboral). Os tribunais superiores de justiça têm quatro divisões (Civil, Penal, Contencioso Administrativo e do Trabalho). São formados por um presidente, que é igualmente presidente das secções civil e penal, pelos presidentes de secção e pelos magistrados estabelecidos por lei para cada uma das suas secções. Os tribunais provinciais são compostos por um presidente e por dois ou mais magistrados. Tratam processos em matéria civil e penal, podendo existir secções com a mesma composição. Disponível em: https://ejustice.europa.eu/content_judicial_systems_in_member_states-16-es-pt.do?member=1.>. Acesso em $03 \mathrm{dez}$. 2016.
} 
[...] Os fatos provados demonstram que o pai do autor do pleito, Dom Juan Francisco, ingressou no hospital geral de Valência em 12 de novembro de 1991, sendo transferido para o hospital Arnaldo de Vila Nova por ter sofrido hemorragia digestiva em estado de coma, sendo diagnosticado com cirrose hepática, que lhe ocasionou o falecimento. O cadáver passou a ser colocado em sala mortuária em cujo lugar disse a sentença $\ll<$ foi notada a sua presença apenas oito dias depois, por uma trabalhadora social do hospital >>, o que motivou a procura da polícia para localizar sua família. A negligência dos serviços hospitalares se demonstrou nos autos e seu reconhecimento foi corretamente decretado pelo tribunal de instância. A impugnação deste recurso está dirigida a combater a indenização por dano moral outorgada na sentença. A sentença recorrida carece de intensidade impugnatória suficiente para decretar que não se tenha gerado no caso dos autos, danos morais, que se apresentam como consequências da negligência dos serviços prestados pelo ente demandado. A jurisprudência consolidada e antiga desta Sala vem considerando a indenização por danos morais, reconhecendo que sua valoração não pode se obter de uma prova objetiva e que se impossibilita aos tribunais mensurar tal dano. [Sentença 22 de fevereiro de 2001. Recurso n. ${ }^{\circ}$ 35811996. Proponente: Exmo. Sr. D. Luis Martinez Calcerrada Gómez].

[...] função esta, revisão do dano moral, igualmente atribuída à sala de instância, não podendo ser revisada em cassação, salvo que se tenham modificado as bases fáticas contempladas para quantificação [...] [STS $15 \backslash 06 \backslash 92$ (Tol 1660743)].

[...] É doutrina consolidada e proferida em inúmeras sentenças desta Sala, a que determina que a fixação da quantia da indenização derivada de uma responsabilidade civil é função atribuída à Sala de instância e não pode ser revisada em cassação, salvo se o modelo determinativo da mesma se incorra em flagrantes contradições ou resultados aritméticos que demonstram os dados de constatação do evento danoso que se trate de restaurar [STS 09\07\03 (TOL 295877)8 $]^{10}$.

Ou seja, a análise dos julgados brasileiros explicita o lugar de hierarquia da corte superior, STJ, que está livremente autorizada, segundo critérios subjetivos, de proporcionalidade e de razoabilidade, a rever o quantum indenizatório fixado nas instâncias inferiores; ao passo que, na Espanha, o critério adotado pelos magistrados ou pelos tribunais de província não pode ser revisto pela corte superior de cassação, que não está, de modo algum, franqueada a superar o entendimento adotado nas instâncias originárias.

As hierarquias decisórias em ambos os sistemas estão situadas, portanto, em espaços de autoridade diferenciados. Aqui, porque o STJ é uma corte superior, a ele cabe a revisão dos julgados. Lá, entende-se que as instâncias inferiores tiveram mais contato com o caso e, por

\footnotetext{
${ }^{10}$ No mesmo sentido: < La función de calcular los daños indemnizables es atribuida exclusivamente por la doctrina jurisprudencial a los órganos judiciales quienes lo llevaran a cabo caso por caso, valorando las probanzas unidas a las acusaciones, sin que puedan hallarse sujetos a previsión normativa alguna, que por su carácter general no permite indivicualización del caso concreto. Así resulta, entre otras muchas, de la Sentencia de 25 de marzo de 1991. Sentencia de 19 de Junio de 1997 > [STS 27\04104 (TOL 365384)].
} 
isso mesmo, quanto ao valor do dano, têm melhores condições de enfrentar o quantum, independentemente do espaço de hierarquia da corte de cassação.

Logo, depreende-se que os dois sistemas jurídicos possuem lógicas completamente distintas para a análise e fixação do valor indenizatório por ofensa a direito da personalidade. Enquanto a última palavra no sistema brasileiro, de fato, pertence a um tribunal superior, no sistema espanhol, a decisão das instâncias inferiores (tribunais de instância) é quase que soberana, não sendo retocada pelo Tribunal de Cassação, sob a alegação de que a melhor análise do dano e parâmetros de reparação é aferida pelo "juiz ou tribunal de instância" de forma discricionária.

\section{Considerações finais: aproximações, deslocamentos e contrastes entre distintas culturas jurídicas}

O estudo permitiu perceber que existem semelhanças e diferenças nos sistemas jurídicos analisados.

A perspectiva legislativa e doutrinária de ambos os sistemas é bastante semelhante, aproximando os sistemas brasileiro e espanhol, sendo certo que, a perspectiva jurisprudencial, entretanto, serviu como marca do importante contraste que distancia o perfil das cortes superiores brasileira e espanhola, uma vez que a principal diferença verificada na pesquisa diz respeito, justamente, à forma como as cortes superiores tratam a indenização por dano moral aqui e lá, e o lugar da autoridade decisória do quantum indenizatório, que aqui está no STJ e lá, nos juízes de $1^{\circ}$ grau e nos Tribunais das províncias.

A nossa proposta, de analisar a problemática referente à quantificação do valor indenizatório por dano moral sofrido e a sua reanálise pelo STJ, no caso brasileiro, e pela corte de cassação, no país ibérico, explicitou um tratamento bastante distinto acerca do papel das cortes superiores nesses países.

Ou seja, embora tanto o Brasil como a Espanha possuam sistemas jurídicos bem parecidos, devido à tradição seguida por ambos, a da Civil Law, é certo que, no que se refere à forma como os sistemas se materializam e sobre como decidem nos casos concretos, verificamos que existem diferenças importantes, especialmente sobre os critérios de julgamento e os espaços de poder decisório. 
Enquanto em nosso país os tribunais superiores criam entendimentos sumulados para reduzir a sua demanda de trabalho e resolver a questão do grande vulto de ações e recursos submetidos a sua apreciação, como ocorreu no caso da súmula 7 do STJ, editada e com aplicabilidade desde o ano de 1990; estes mesmos órgãos, de forma aparentemente paradoxal, flexibilizam esse mecanismo quando querem enfrentar certas questões de mérito e revisar decisões consolidadas nas instâncias anteriores, explicitando certa discricionariedade no tratamento dos processos e sugerindo que têm o poder final de decisão e a autoridade sobre o que julgar, em função de uma hierarquia de graus de jurisdição que se reflete em uma hierarquia de poder.

O sistema espanhol, no entanto, lida com a hierarquia de graus de jurisdição de forma bastante distinta. A corte de cassação, embora superior hierárquica em grau de jurisdição, está restrita e limitada em seu poder de decisão pela autoridade das instâncias inferiores, ao menos no que se refere ao tema desta pesquisa, relacionada ao valor do dano moral.

Percebemos que o sistema espanhol trata de forma diferente a questão da reanálise do mérito quando envolvida questão de arbitramento de quantia indenizatória por dano imaterial, conferindo maior autonomia aos magistrados de instância inferior.

Lá, o papel das cortes superiores parece ser menos centralizador, pois existe a chamada discricionariedade do juiz de instância no tocante à fixação de valores indenizatórios por dano imaterial. Ou seja, o Tribunal de Cassação espanhol não adentra no mérito do quantum indenizatório, sendo certo que o que for arbitrado pelos juízes "de instância", será, sempre, a palavra final.

Aqui, no Brasil, não.

As hierarquias decisórias em ambos os sistemas estão situadas, portanto, em espaços de autoridade diferenciados e as hierarquias de instância assumem papeis igualmente distintos no sistema processual.

Em termos políticos, também é muito interessante perceber que, aparentemente, o nosso sistema é classificado como uma democracia republicana, avessa à centralização de poderes e distinção de direitos perante a lei, enquanto a Espanha está regida por um sistema monárquico constitucional. No entanto, em termos jurisprudenciais, o nosso STJ parece exercer uma função bastante mais centralizadora do que a corte espanhola, que delega e 
franqueia aos magistrados de província a autoridade de decidir, concretamente, sobre os valores indenizatórios em ações de danos morais.

Ou seja, tais circunstâncias, políticas e jurídicas, dizem muito sobre o tema aqui estudado e, ainda mais, sobre o nosso sistema de justiça, tendo em vista que, analisando as características da jurisprudência dos dois países, podemos concluir que nosso modelo é mais centralizador (mesmo se tratando de um país democrático republicano) enquanto o modelo espanhol é menos centralizador. Nessa linha, as características dos sistemas nos parecem “trocadas". Enquanto nosso modelo deveria ser menos centralizador, não o é, ao contrário do modelo jurisprudencial espanhol.

Em síntese, portanto, o contraste da jurisprudência permitiu perceber que, no Brasil, o Superior Tribunal de Justiça tem um papel importante na concessão das indenizações e que, apesar da súmula 7, que impediria o revolvimento das questões fáticas atinentes à responsabilidade civil, ainda assim, a corte pode, casuisticamente, reduzir ou aumentar o valor do dano moral concedido nas instâncias estaduais. Na Espanha, diferentemente do que ocorre em nosso país, o sistema processual confere maior autonomia aos magistrados de instância inferior no tratamento do dano moral, sendo certo que o papel da corte superior é menos centralizador. A análise dos julgados espanhóis permitiu perceber que vige, naquele sistema, a discricionariedade do juiz de instância no tocante à fixação de valores indenizatórios por dano imaterial, de forma que o papel daquela corte é bastante distinto e restrito em relação ao que se verificou no STJ.

Entre aproximações legislativas, distanciamentos jurisprudenciais e perplexidades políticas, o estudo comparado, direcionado a identificar semelhanças e diferenças entre o Brasil e a Espanha, acabou se mostrando muito propício e profícuo na compreensão do nosso próprio sistema.

\section{Referências bibliográficas}

AFONSO DA SILVA, Virgílio. O Proporcional e o Razoável. Revista dos Tribunais, n. 798, 2002.

ALEXY, Robert. Teoria dos Direitos Fundamentais. 2 ed. São Paulo: Malheiros. 2011. 
BARROSO, Luís Roberto. Curso de Direito Constitucional Contemporâneo. 6. ed. São Paulo: Saraiva, 2011.

BITTAR, Carlos Alberto. Reparação civil por danos morais. 4a . ed. São Paulo: Saraiva, 2015.

BUSTO LAGO, J. M. y PEÑA LÓPEZ, F. Enriquecimiento injusto y responsabilidad civil extracontractual. Anuario de la Facultad de Derecho de la Universidad de Coruña, $n^{\circ} 1$, 1997.

CASADO, Esther Monterroso. Derecho civil. Derecho de las obligaciones. $3^{\mathrm{a}}$. ed. Madrid: Ediciones CEF, 2015.

CASTILLO MARTÍNEZ, C.C. La indemnización por daños y la problemática de su cuantificación (cuestiones escogidas). Actualidad Civil (edición digital), $n^{\circ} 41$. Edit. Reus, Madrid, 2003.

CAVALIERI FILHO, Sérgio. Programa de responsabilidade civil. 11. ed. São Paulo: Atlas, 2012.

FARIAS, Cristiano Chaves de, e ROSENVALD, Nelson. Curso de direito civil, vol. 1, 11. ed. Salvador: Jus Podium, 2013.

FERNÁNDEZ, Maria Serrano e outros. Tratado Jurisprudencial de responsabilidad por daños. 11 ${ }^{\mathrm{a}}$. ed. Valencia. Tirant, 2013.

GABRIEL, José Ramón Ferrándiz; TRIAS, Encarnación Roca. Reeponsabilidad civil. Cuestiones generales y su efecto reparador. $3^{\mathrm{a}}$. ed. Madrid: La Ley, 2010.

GONÇALVES, Carlos Roberto. Responsabilidade civil. 14. ed. São Paulo: Saraiva, 2012.

LUPETTI BAPTISTA, Bárbara Gomes. Paradoxos e ambiguidades da imparcialidade judicial: entre "quereres" e "poderes". Porto Alegre: Ed. Sergio Antonio Fabris, $2013 a$.

Uma análise empírica sobre os reflexos da hermenêutica jurídica e da técnica da ponderação de princípios no exercício da jurisdição. Lex Humana, Petrópolis, v. 5, n. 2, p. 2246, 2013b.

LUPETTI BAPTISTA, Bárbara Gomes; PUERARI, Daniel. O USO DOS PRINCÍPIOS DA PROPORCIONALIDADE E DA RAZOABILIDADE EM AÇÕES INDENIZATÓRIAS: um 
escudo retórico de sofisticação para o subjetivismo implícito. In: XXV Encontro do Conpedi, Direitos e Garantias Fundamentais II. Brasília: Conpedi, 2016. v. 1. p. 248-266.

MENDES, Gilmar Ferreira; BRANCO, Paulo Gustavo Gonet. Curso de Direito Constitucional. São Paulo: ed. Saraiva, 2015.

SARLET, Ingo Wolfgang. A eficácia dos direitos fundamentais: uma teoria dos direitos fundamentais na perspectiva constitucional. 12a . ed. Porto Alegre: Revista do advogado editora, 2015.

SARMENTO, Daniel. Livres e Iguais: Estudos de Direito Constitucional. São Paulo: Lumen Juris, 2006. 